\title{
Modelo de competência para ambiente hipermídia*
}

\author{
Research on lexical competence in hypermedia \\ learning environment
}

\section{Patrícia Nora de Souza Universidade Federal de Juiz de Fora}

\section{Abstract}

The present literature on the use of computer in foreign language classroom points out the important role hypermedia plays to lexis teaching and learning in a foreign language. However, there aren't studies which address aspects of knowledge or competences required for lexis learning mediated by hypermedia, so that it can be more significant and efficient. Considering that, the present work is aimed at discussing a proposal of a lexical competence model for hypermedia environment, offering, in this way, theoretical support to teachers and researchers in lexis teaching and learning in this new scenery.

\section{Keywords}

Lexical competence, Hipermedia, Foreign language

\section{Resumo}

A literatura atual sobre o uso do computador na sala de aula de língua estrangeira aponta o papel importante da hipermídia para o ensino/aprendizagem do léxico em língua estrangeira. Entretanto, são poucos os estudos que focam os aspectos do conhecimento ou competências necessários para o aprendizado do léxico mediado pela hipermídia, de forma que este seja mais eficiente e significativo. Nesse sentido, o presente trabalho objetiva 
discutir uma proposta de um modelo de competência lexical, oferecendo, assim, subsídios teóricos para professores e pesquisadores para o uso da hipermídia no ensino/aprendizagem do léxico

\section{Palavras-chave}

Competência lexical, Hipermídia, Língua estrangeira 


\section{INTRODUÇÃO}

E mbora estudos sobre os impactos do uso do computador na área da educação sejam recentes e careçam de maiores investigações, muitos pesquisadores têm defendido a tese de que esse artefato pode contribuir significativamente para o aprendizado. Esse fato se deve, em parte, principalmente à capacidade do computador de possibilitar a criação de materiais instrucionais multimodais.

Não se deve, entretanto, considerar a multimodalidade como algo novo e/ou particular do meio digital, apesar de ser, sem dúvida alguma, por ele facilitada. Como aponta Kress, a comunicação é multisemiótica. O que está acontecendo não é novo. No entanto, é uma mudança significativa. ${ }^{1}$ Recursos áudio-visuais, tais como o gravador, o vídeo, que, entre outros recursos, geralmente acompanham as atividades propostas pelo livro didático, sempre fizeram parte da sala de aula de línguas. A diferença é que a inclusão do computador nesse contexto rompe com a linearidade proposta nos livros didáticos, favorecendo a integração desses recursos multimodais que podem ser combinados para fornecer contraste, justaposição, complementaridade e conexão de informações (WARSCHAUER, 1999). Além disso, permite que o aluno interaja com o material e recursos didáticos, participando ativamente do processo ensino-aprendizagem, porque faz as escolhas que atendam mais as suas necessidades e ou estilo cognitivo.

É essa capacidade de integrar formas diferentes de representação da informação e acesso não linear ao material, portanto, que faz da tecnologia hipermídia, proporcionada pelo computador, um recurso valioso para o aprendizado.

Cabe ressaltar aqui que, embora haja na literatura atual um consenso quanto à relevância dessa tecnologia para o aprendizado, 
no que se refere ao ensino e aprendizagem do léxico em LE, não existem esforços de pesquisa voltados à investigação de modelos de competência lexical que orientem o aprendizado em ambiente hipermídia. Em outras palavras, carecemos de estudos que reflitam sobre aspectos do conhecimento e competências a serem desenvolvidos nos alunos, a fim de que esse ambiente possa, de fato, contribuir para o aprendizado. Reconhecendo tal carência, o presente trabalho busca discutir uma proposta de modelo de competência lexical para o ambiente hipermídia. Mais especificamente, objetiva-se refletir sobre aspectos do conhecimento e competências necessárias para o aprendizado do léxico no ambiente hipermídia.

Para o alcance do objetivo proposto, o trabalho foi organizado em 5 seções. A seção 1 introduz o problema de pesquisa e seu contexto. A seção 2 discute as vantagens pedagógicas da hipermídia para a aquisição de língua estrangeira, em geral, e a seção 2.1 reúne pesquisas voltadas para o ensino e aprendizagem do léxico no ambiente hipermídia, em particular. A seção 3 traz uma revisão crítica dos modelos de competência lexical propostos na literatura para o ensino e a avaliação do léxico. A seção 4 discute aspectos do conhecimento ou competências necessárias para o aprendizado através da hipermídia, propondo um modelo de competência lexical que oriente o ensino e a aprendizagem nesse novo ambiente. A seção 5 apresenta as conclusões do presente estudo, assim como as perspectivas futuras de trabalho na área de ensino do léxico mediado por computador.

\section{VANTAGENS PEDAGÓGICAS DA HIPERMÍDIA}

O hipertexto pode ser definido como uma forma de organização dos textos através de links eletrônicos, os quais permitem conexões entre palavras, seções de um mesmo hipertexto ou relações interhipertextuais (BRAGA, 2003) que motiva uma leitura descontínua, interativa e associativa. Quando essa estrutura acomoda não somente texto verbal, mas igualmente som digitalizado, gravuras, animação, 
vídeo, ela é denominada hipermídia. Entretanto, o termo hipertexto tem sido usado indiscriminadamente na literatura referindo-se não somente a textos verbais, mas também a textos que incluem recursos multimídia. Braga (2004), baseada no estudo de Lemke (2002), define a hipermídia como sendo caracterizada pela interatividade promovida pela estrutura hipertextual e a integração de diferentes modalidades.

Estudos recentes, preocupados de forma mais específica com a criação de ambientes de aprendizagem hipermídia para o ensino da LE, apontam as vantagens da inserção do computador na sala de aula de línguas. Dentre essas vantagens, destaca-se que tal ferramenta viabiliza a integração de informações lingüísticas e extralingüísticas, presentes em contextos reais de uso da língua, as quais podem contribuir significativamente para a solução de problemas de compreensão tanto no nível do processamento ascendente (bottomup) quanto no nível do processamento descendente (top down). Adicionalmente, o uso de várias mídias, nesse ambiente pode favorecer o aprendizado da língua-alvo através do efeito de saliência propiciado pela re-apresentação das informações. Para Meskill (1996), tal efeito proporcionado pela hipermídia pode ser fornecido, por exemplo, pelos visuais que oferecem suporte à compreensão do insumo oral e/ou escrito em língua estrangeira. Esse apoio faz com que haja menos gastos de energia no processamento, reduzindo, assim, a sobrecarga cognitiva que geralmente é enfrentada pelo aprendiz de língua estrangeira, principalmente em contato com materiais autênticos. Os recursos cognitivos que ficam disponíveis podem ser direcionados, portanto, a outros processos, tais como inferência e elaboração do insumo recebido.

Nessa mesma direção, Braga (2004) conjectura que o uso da tecnologia hipermídia pode favorecer a construção de textos e materiais mais didáticos, já que uma mesma informação pode ser complementada, reiterada e mesmo sistematizada ao ser apresentada ao aprendiz na forma de um complexo multimodal. Em outras palavras, para a autora, a apresentação de uma mesma informação, através de diferentes modalidades, pode ser explorada de modo a 
gerar reapresentações diferenciadas de uma mesma informação, o que possibilita que o mesmo sentido seja reforçado simultaneamente por mais de um canal de recepção, podendo também especificar ou mesmo ampliar certos sentidos. Uma outra questão, do ponto de vista pedagógico, apontada na literatura atual sobre ambientes hipermídia e o aprendizado de língua estrangeira, é a existência da possibilidade de que a informação processada em diferentes canais possa beneficiar alunos que têm capacidades cognitivas distintas, ou seja, melhor memória visual, verbal ou sonora. As pessoas aprendem de forma diferente e o material hipermídia permite melhor atender a diferentes necessidades e estilos cognitivos. A possibilidade de escolhas favorecida pela estrutura hipertextual torna possível ao aprendiz determinar a trajetória e as combinações que melhor apóiam suas interações com as informações veiculadas pelo material, facilitando assim a aquisição do conhecimento. Mesmo considerando que os links informativos disponibilizados na tela para o aluno foram previamente escolhidos pelo professor, a partir de objetivos didáticos pré-estabelecidos, no ambiente hipermídia de ensino, cabe ao aluno e não ao professor determinar quais informações multimodais serão acessadas, bem como a ordem de exploração dessas informações. Em outras palavras, é o aluno, em última instância, quem decide, de acordo com suas dificuldades e interesses, como combinar e associar as diferentes informações de forma a apoiá-lo no processo de construção de significados e também determinar o tempo a ser destinado a cada uma dessas atividades. Desta forma, o ambiente hipermídia contribui para que o aprendiz explore e reflita sobre suas preferências individuais, desafiando-o e motivando-o a um maior engajamento em seu processo de aprendizagem. (SOUZA, 2004; BRETT, 1995)

A hipermídia favorece ainda a compreensão de língua "como prática comunicativa”, propiciando ao aluno o acesso a informações que normalmente são disponíveis em um contato autêntico com a língua e que são imprescindíveis à compreensão.

Antes de concluirmos esta seção, não podemos deixar de comentar que alguns autores (MAYER, 2001; SOUZA, 2004) adotam 
uma posição menos otimista e alertam para o fato de que a multimodalidade, numa situação de ensino, pode ser mais prejudicial do que benéfica, principalmente se não for usada de forma apropriada, ou seja, caso as diferentes mídias não sejam combinadas de forma eficaz. Considerando a elaboração de materiais pedagógicos, é importante ressaltar que nem sempre a multimodalidade é o caminho mais eficiente ou necessário. Por exemplo, certos tipos de tarefa multimodal podem não promover o aprendizado, especialmente se o uso da multimodalidade não tem um objetivo claro ou se há excesso de informação. Essa é uma preocupação que tem orientado pesquisas, ainda em número reduzido, que investigam o uso apropriado das várias mídias para a construção de conhecimento. Dentre esses poucos trabalhos na área de língua estrangeira, destaca-se o estudo de Souza (2004) que apresenta princípios para a construção de materiais instrucionais em ambiente hipermodal.

A seção que se segue amplia as reflexões sobre a relevância pedagógica da hipermídia, enfocando uma questão especifica: o ensino e a aprendizagem do léxico.

\subsection{Pesquisas sobre o ensino e a aquisição do léxico em LE em ambiente hipermídia}

Como discutimos anteriormente, as possibilidades de criação de ambientes hipermídia de aprendizagem, proporcionadas pelo computador, por explorarem de forma não linear, porém, integrada tanto os recursos lingüísticos quanto extralingüísticos, podem conferir maior autenticidade ao processo de aprendizagem de línguas. No contexto específico de ensino da língua estrangeira mediada por computador, pesquisadores têm devotado considerável atenção ao papel que a hipermídia desempenha no desenvolvimento do conhecimento lexical. Os resultados obtidos sugerem impactos positivos quanto aos diferentes usos da tecnologia hipermídia: anotações na forma de glossário, dicionário eletrônico e concordancer, entre outros, no aprendizado implícito de vocabulário, ${ }^{2}$ em particular e, de forma mais geral, na compreensão de textos. 
Focando inicialmente o papel do glossário multimídia no processo de compreensão, Chun e Plass (1996) discutem os resultados de três estudos realizados no ambiente de aprendizagem CyberBush - uma aplicação hipermídia para a leitura de textos em alemão. Esse ambiente contém uma variedade de anotações para as palavras na forma de texto, figura e vídeo que têm o objetivo de ajudar na compreensão e aprendizagem do vocabulário. (Um exemplo exemplo de glossário multimídia presente no ambiente de aprendizagem CyberBush pode ser visto no seguinte endereço: http:/ /www.gss.ucsb.edu/faculty/dmchun/cyberbuch/Links.html).

Os estudos de Chun e Plass (1996) revelam que as aplicações hipermídia contribuem significativamente para a aprendizagem implícita de vocabulário. Considerando a integração das modalidades contrastadas: texto + figura e vídeo + texto, os resultados obtidos em seus estudos indicaram que as anotações na forma de texto juntamente com figura contribuíram mais para o aprendizado dos leitores que a integração de texto e vídeo, ou do texto apresentado isoladamente.

Na mesma direção, Al-Seghayer (2001) também investigou os impactos da hipermodalidade no aprendizado implícito de vocabulário, a partir de um programa de aprendizado hipermídia. O programa ofereceu aos 30 participantes da investigação a leitura de um texto narrativo em inglês com uma variedade de anotações (glosses) para as palavras, a fim de favorecer a compreensão e também o aprendizado das palavras desconhecidas. Foram testadas a eficiência de três tipos de anotações multimídia para o aprendizado incidental: anotações na forma de texto; texto + gravuras; e de texto + vídeo. Os resultados obtidos apontam o vídeo como um recurso mais eficiente do que as gravuras, resultado este que se difere daquele obtido por Chun e Plass (1996). Dentre as suposições levantadas por Al-Seghayer para justificar os resultados conflitantes obtidos, destacam-se as diferenças na metodologia de pesquisa e no perfil dos participantes das pesquisas. Apesar dos resultados serem conflitantes no que concerne à eficiência de determinadas mídias no aprendizado, o fato é que ambos os estudos evidenciam a relevância da hipermodalidade, com destaque para o glossário, no aprendizado implícito de vocabulário. 
A relevância do glossário multimídia no aprendizado implícito de vocabulário, através da uma atividade de compreensão de texto, foi igualmente o foco de um estudo de Lyman-Hager et alii (1993). Na pesquisa conduzida pelos autores foram avaliados o comportamento de dois grupos de leitores: leitores de texto com glossário multimídia e leitores de texto impresso acompanhado de glossário convencional. Os resultados obtidos apontam que, na condição comparativa, o grupo de leitores de texto com glossário multimídia apresentou melhor desempenho, evidenciando que a multimídia contribuiu positivamente para a retenção de vocabulário. A relevância do glossário multimídia centra-se no fato deste oportunizar o acesso a várias informações em diferentes mídias, como já explicitado anteriormente, bem como o acesso rápido ao significado, bastando apenas um clique sobre a palavra-alvo anotada, o que evita interrupções no processamento da leitura (Al-Seghayer, 2001).

Em relação ao uso do dicionário eletrônico no aprendizado de línguas, as pesquisas têm também investigado os impactos desse recurso on-line tanto no aprendizado implícito de vocabulário quanto na compreensão textual. No que concerne especificamente ao uso do dicionário para o aprendizado implícito de vocabulário, Laufer e Hill (2000) investigaram a relação existente entre a seleção de informações multimodais sobre as palavras desconhecidas e a retenção do significado das mesmas por aprendizes de inglês como LE. Os resultados do estudo sugerem que os alunos têm preferências diferentes na seleção e busca de informação, porém, independentemente das preferências individuais, observou-se que o uso do dicionário eletrônico com informações multimídia reforça a retenção do vocabulário.

Knight (1994) em um estudo com aprendizes de espanhol também investigou os impactos do dicionário eletrônico no aprendizado implícito de vocabulário quanto na compreensão de textos. Os sujeitos da pesquisa foram divididos em dois grupos de acordo com sua proficiência lingüística na língua-alvo: um grupo que teve acesso ao dicionário para a leitura de textos e o outro grupo foi orientado a 
ler os textos e a inferir os significados das palavras desconhecidas sem recorrer ao dicionário como recurso de apoio. Os resultados obtidos nos testes de vocabulário aplicados após a atividade de leitura dos textos evidenciaram que os alunos que usaram o dicionário demoraram mais para ler os textos, porém,os resultados foram superiores aos daqueles que recorreram à inferência para resolver problemas com o vocabulário desconhecido durante a leitura. Observou-se ainda que alunos que possuíam menor proficiência na língua alvo se beneficiaram mais do uso do dicionário. Esse estudo aponta, assim, que a aquisição implícita de vocabulário através do uso do dicionário realmente ocorre durante a leitura, sendo esse recurso indicado principalmente para aprendizes que possuem pouco conhecimento da língua alvo e que são menos capazes de realizar inferências corretas.

Zahner, Gupta e Olohan (1994) em seus estudos também apontam impactos positivos do uso do dicionário eletrônico no aprendizado implícito de vocabulário. Eles atribuem tais resultados à possibilidade do acesso a uma variedade de informações em diferentes mídias, apresentadas de forma não linear e em camadas que pode reduzir a sobrecarga cognitiva, que geralmente está presente no manuseio das complexas entradas de informações fornecidas pelo dicionário impresso. A apresentação em camadas possibilita, inicialmente, que o aprendiz tenha acesso à informações essenciais e, posteriormente, conforme necessário e/ou desejado explore detalhadamente o item lexical desconhecido.

Uma outra ferramenta online que tem sido investigada para a aquisição de vocabulário, esta usada com menor freqüência em sala de aula, é o programa concordancer. Essa ferramenta pode ser definida como um programa de computador simples que permite uma busca construtiva de uma grande quantidade de textos (concordances ${ }^{3}$ ) para exemplificar os significados e usos de uma determinada palavra ou frase (LEWIS, 2000). A maioria dos programas permitem ao usuário determinar a quantidade e o tipo de contexto a serem acessados. As variações típicas de contexto apresentadas pelos concordancers incluem: sentença, parágrafo completo e etc, Um 
exemplo desse tipo de programa é encontrado no endereço http:// www.edict.com.hk/concordance/default.htm.

Apesar de sua aplicação recente para o aprendizado de línguas, estudos nos últimos anos começam a reconhecer as potencialidades da ferramenta concordancer para o ensino e a aquisição lexical tanto explícitos quanto implícitos. Pesquisadores como Hardisty and Windeatt (1989), Thurstun e Candlin (1998) têm proposto o seu uso para a elaboração de material instrucional, focando o vocabulário e a gramática. Dentre as vantagens apontadas por tais teóricos para o uso desse tipo de ferramenta para a aquisição de vocabulário estão as seguintes:

a) a apresentação do vocabulário em contextos reais de uso da língua;

b) a apresentação da palavra/frase em contextos múltiplos que fornecem informação sobre uma variedade de aspectos do conhecimento da palavra, incluindo colocações, padrões gramaticais, relações semânticas entre as palavras (sinonímia, antonímia), entre outros.

Entretanto, ainda são poucos os estudos empíricos que apontam a eficiência dessa ferramenta para o ensino do vocabulário. Dentre esses estudos, destacamos o de Cobb (1997) que investiga a hipótese de que a ferramenta concordancer pode estimular a aquisição do vocabulário ao apresentar as palavras em vários contextos. Nessa investigação duas situações de aprendizagem foram comparadas: uma situação em que foi usado o programa concordancer denominado Pet 200, desenvolvido pelo próprio pesquisador, para o aprendizado de vocabulário e outra que envolvia o uso de outras fontes de informação. Para testar sua hipótese, Cobb (1997) comparou o desempenho dos participantes em uma série de testes, envolvendo a transferência de conhecimento das palavras-alvo destacadas para novos contextos. Os resultados obtidos apontam um ganho pequeno, porém, significativo para as palavras apresentadas através da ferramenta concordancer. 
Thurstun e Candlin (1998) também estudam essa questão. Os autores desenvolveram o programa Microconcord para apoiar o desenvolvimento de materiais de ensino para o estudo independente do vocabulário do inglês acadêmico. Professores e alunos que utilizaram esse concordancer relataram sua utilidade para a aquisição do vocabulário, com destaque para colocações, e também apontaram que as oportunidades oferecidas pela ferramenta foram úteis para a ampliação da consciência lexical e gramatical dos alunos.

Souza (2004) também aponta, em seu estudo sobre o ensino e aquisição implícitos e explícitos de vocabulário em contexto da leitura em LE, a relevância deste ambiente para a aquisição lexical.

O que fica claro nessa breve revisão da literatura é que pesquisas sobre o ensino e aquisição do léxico no ensino da leitura em LE mediado por computador oferecerem evidências dos efeitos positivos do uso da hipermídia. A relevância deste ambiente, no entanto, aponta a necessidade de refletirmos sobre os aspectos do conhecimento e competências que norteiem o ensino do léxico nesse novo contexto de aprendizagem. Essa questão será discutida mais adiante. Anterior a essa questão está uma revisão crítica dos modelos de competência lexical existentes na literatura, apresentada na seção que se segue.

\section{MODELOS DE COMPETÊNCIA LEXICAL}

Pesquisadores em leitura em língua estrangeira têm buscado caracterizar o conhecimento/competência lexical do leitor-aprendiz de língua estrangeira para o uso eficiente da língua. A literatura aponta vários embates teóricos nessa direção que revelam abordagens de pesquisa bastante diversificadas.

\subsection{Abordagem quantitativa versus qualitativa}

O conhecimento lexical em língua estrangeira tem sido investigado tanto em perspectiva quantitativa (breadth of vocabulary 
knowledge), ou seja, com ênfase na existência de um número mínimo de palavras necessário para a compreensão, quanto qualitativa (depth of vocabulary knowledge), com ênfase nos vários níveis e dimensões desse conhecimento.

A orientação quantitativa de pesquisa, segundo Nation e Waring (1997), busca responder a seguinte pergunta: quantas palavras o aprendiz de L2/LE precisa conhecer para o uso eficiente da língua? Esforços no sentido de responder a questão são vários e geralmente focam um contexto particular de uso.

Laufer (1991), em um estudo com 92 alunos de inglês como língua estrangeira, investigou um nível mínimo de conhecimento lexical necessário para a compreensão. Os sujeitos do estudo foram divididos em 5 grupos de acordo com seu nível de conhecimento lexical: aqueles que apresentavam um conhecimento de 2.000, 3.000, 4.000 e 5.000 famílias de palavras. ${ }^{4}$ Os resultados obtidos sugerem um nível mínimo de conhecimento em torno de 3.000 a 5.000 famílias de palavras para a compreensão. É nesse limiar de conhecimento que, segundo Laufer (1991), bons leitores em L1 são capazes de transferir suas estratégias de leitura para L2. No ano seguinte, Laufer (1992) reafirma os resultados obtidos com esse estudo através da comparação da relação entre conhecimento lexical, compreensão em leitura e habilidade acadêmica geral (que incluiu a leitura em L1). A comparação apontou que os aprendizes de inglês como LE que possuíam um conhecimento de vocabulário abaixo do limiar de 3.000 palavras tiveram um fraco desempenho nos testes de leitura, independente de sua habilidade acadêmica geral. Assim, mesmo sendo bons leitores em L1, devido ao baixo nível de conhecimento lexical, alguns participantes não apresentaram um bom desempenho na leitura em L2. Resultados semelhantes foram apresentados por Schmitt e McCarthy (1997), Nation e Waring (1997) os quais apontam para o inglês igualmente um nível limiar de, no mínimo, 3.000 famílias de palavras, ou seja, 5.000 itens lexicais de alta freqüência para a compreensão de textos autênticos.

Tais resultados indicam que parece haver na literatura um consenso entre pesquisadores quanto a um limiar de conhecimento 
lexical, em particular, para a compreensão e/ou inferência lexical. Segundo Laufer (1997), a necessidade de um nível limiar de conhecimento lexical para que a compreensão e/ou inferência lexical sejam possíveis, evidenciado pelas pesquisas aqui discutidas, pode ser explicada pelo fato de que este conhecimento contribui substancialmente para que o leitor empregue menos capacidade cognitiva para o processamento do texto a nível ascendente, ou seja, para a decodificação de palavras e, portanto, disponha de mais capacidade cognitiva para o processamento do texto no nível descendente. Maiores investigações precisam ser feitas no sentido de caracterizar melhor esse limiar de conhecimento, visto ainda como uma medida aproximada de conhecimento.

Apesar da relevância dessa abordagem quantitativa de pesquisa na medida em que aponta o papel importante que o conhecimento lexical desempenha na compreensão e/ou inferência lexical, estudos têm apontado, entretanto, que a competência lexical não deve ser descrita somente em termos quantitativos, mas também qualitativos. O aprendizado do léxico, segundo essa perspectiva qualitativa, é um processo dinâmico e gradual que envolve diferentes graus de conhecimento que vão variar, para Alderson (1984), segundo o tipo de tarefa, o tipo de texto e o desenvolvimento cognitivo e conceitual (ou prévio) do leitor. Os modelos de competência lexical diferem na caracterização desses graus de conhecimento e nos tipos de testes requeridos para avalia-lo.

O conceito rico de Richards (1976), ${ }^{5}$ proposto para o falante nativo ideal, tem sido uma referência para orientar pesquisas na área do ensino e a aprendizagem do léxico, assim como a avaliação do conhecimento lexical adquirido pelo aprendiz de LE.

Scaramucci (1995) propõe um modelo de competência lexical denominado conceito rico de vocabulário que é uma adaptação do conceito de competência lexical proposto por Richards. O modelo de Scaramucci além da dimensão de conhecimento, proposto por Richards, que apenas contempla os níveis lexical, sintático, morfológico e semântico, considera também a dimensão de uso, no nível discursivo-pragmático. 
Sintetizando, para Scaramucci (1995: 83), os conhecimentos que envolvem um conceito rico de competência lexical são:

- o lexical é relacionado ao aspecto formal (ortografia), sonoro (fonético) e morfológico (com destaque para o prefixo e o radical);

- o sintático leva em conta a posição da palavra e sua função, considerando tanto o contexto imediato quanto sua relação com porções maiores do texto, os seus padrões de comportamento sintático na oração, classes gramaticais e morfologia (com destaque para os sufixos);

- o semântico envolve o significado da palavra dentro da oração e seus vários significados formando redes de associações sintagmáticas (de contraste ou antonímia, sinonímia, classificação subordinativa, coordenativa e superordenada) e colocações. Além de aspectos como adequação e freqüência das palavras; referentes e variações no uso da palavra em contextos diversificados.

- o conhecimento prévio ou de mundo refere-se ao conhecimento conceitual ou do assunto, e ainda ao conhecimento sócio-histórico, cultural, crenças, valores ou conhecimento esquemático;

- conhecimentos textuais que se utilizam da organização ou macroestrutura do texto ou estrutura retórica, subtítulo e título;

- conhecimentos superestruturais ou referentes à estrutura canônica de cada tipo de discurso.

Um modelo de competência lexical que contemple os vários níveis de conhecimento, como o proposto por Scaramucci (1995), tem sido respaldado pela literatura. Fender (2001), por exemplo, ao investigar a natureza e o desenvolvimento das habilidades fluentes de integração da palavra em L2 no processamento do texto a nível ascendente, também defende um modelo de competência lexical mais amplo que envolva não só uma dimensão de conhecimento mais também de uso.

Schmitt (1998), Schmitt e Meara (1997) apontam, entretanto, a dificuldade em se usar de forma prática essa abordagem qualitativa para o ensino e a aquisição de vocabulário, uma vez que ela geralmente se baseia em listas de conhecimento de vocabulário puramente descritivas e não auto-explicativas. Ou seja, não há nenhuma orientação quanto à ordem ou a como abordar todo este 
conhecimento em sala de aula. São, portanto, mais apropriadas, segundo esses autores, a um contexto de pesquisa. Entretanto, essa lista de conhecimentos, a nosso entender, tem sua relevância para o ensino e aquisição de vocabulário em LE, na medida em que pode funcionar como uma referência teórica para a preparação de materiais instrucionais. Como bem afirma Richards (1976), seu objetivo ao propor o modelo de competência lexical rico, que tem atualmente fundamentado muitos estudos, "é sugerir que ao prepararmos materiais instrucionais estes sejam fundamentados em um conceito rico de vocabulário". (1976: 118)

Essa breve revisão da leitura sobre modelos de competência lexical que norteiam o ensino e aquisição do léxico acusa a falta de um modelo voltado especificamente para o ambiente hipermídia. Tal questão, não sinalizada na literatura, a meu ver, merece atenção, e, portanto, ganha espaço na seção seguinte do presente trabalho.

\section{MODELO DE COMPETÊNCIA LEXICAL PARA AMBIENTE HIPERMÍDIA}

Como já explicitado anteriormente, com a inserção do computador na sala de aula de línguas, em particular, da hipermídia, formas novas e variadas de interação e de construção do conhecimento lexical são oferecidas. Reconhecendo a importância de um modelo de competência lexical para nortear o ensino e a avaliação do léxico, tais alterações nos levam a refletir sobre a validade dos modelos propostos na literatura, discutidos na seção 3, para nortear o ensino do léxico em LE nesse novo contexto de aprendizagem.

Essa reflexão sobre os aspectos do conhecimento e competências que são relevantes para o aprendizado através da ferramenta hipermídia e que, portanto, deveriam ser contemplados em um modelo de competência lexical, é fundamental e urgente na medida em que contribui para que o potencial desse novo ambiente seja devidamente explorado por professores e aprendizes e possa, de fato, cooperar para um aprendizado mais rico e significativo. 
Um modelo de competência lexical para esse ambiente, a meu ver, deve inicialmente considerar, em concordância com o conceito rico de vocabulário proposto por Scaramucci (1995), explicitado na seção anterior, o conhecimento lingüístico e cognitivo, a gramática (sintaxe e morfologia) e o léxico, além de conhecimento prévio ou de mundo. Tal conhecimento construído não pode ser descartado. Ao contrário, é sobre seus ombros que apoio minha reflexão.

Cabe destacar, no entanto, com base nos resultados de experimentos realizados por Souza (2004), que objetivou verificar o papel da hipermídia no aprendizado de vocabulário, em que situações esta tecnologia favoreceria o aprendizado, a fim de orientar o ensino neste ambiente e evitar que esforços materiais e financeiros para a construção de ambientes de aprendizagem hipermídia sejam desperdiçados.

No que se refere ao aprendizado implícito (Para uma definição do termo vide nota de rodapé 2.), o ambiente hipermídia, com destaque para o vídeo (som+imagem) e transcrição (texto verbal), contribui principalmente para o aprendizado de palavras-chave do assunto, servindo as diferentes mídias de apoio para a realização de inferências e retenção do vocabulário novo. Nesse contexto hipermodal, a apresentação simultânea da imagem e do som é fundamental para o processo inferencial, principalmente dos aprendizes principiantes, pois fornece saliência às palavras-alvo e também facilita a consulta à transcrição do vídeo (texto verbal) (SOUZA, op. cit: 227).

Na abordagem explícita (Para uma definição do termo vide nota de rodapé 2.), diferentemente da implícita, a influência positiva da hipermodalidade não é restrita às palavras-chave do assunto tratado. Ela é particularmente eficiente para o ensino de colocações e do valor semântico das palavras considerando seus vários significados e usos (SOUZA, op. cit: 229). ${ }^{7}$

Discutir o ensino e aquisição do léxico através da hipermídia, no entanto, coloca-nos frente a necessidade de um trabalho não apenas no nível do conhecimento lexical. O uso da hipermídia como 
ferramenta mediadora do aprendizado do léxico demanda, de nós professores a exploração de como esse conhecimento se apresenta ou como a construção do mesmo se dá nesse novo ambiente de aprendizagem. Em outras palavras, devemos levar o aprendiz a compreender como a estrutura hipermídia, que faz uso de uma variedade de modos de comunicação - falado, escrito, visual, sonoro, espacial, ao mesmo tempo (KRESS e VAN LEEUWEN, 1996), produz significado em uma multiplicidade de formas, já que ela tem um impacto positivo na realização de inferências e retenção do vocabulário trabalhado. Tal impacto se deve ao fato da hipermodalidade propiciar maior compreensão e retenção do vocabulário pela produção de pistas de memória mais fortes e caminhos de recuperação mais acessíveis, através da re-apresentação de informações nas várias mídias, assim como pelo esforço mental que é despendido na integração das informações hipermodais na busca de sentido.

Assim, é de suprema importância o conhecimento, por parte de professores e aprendizes, de como as várias mídias são utilizadas para criar significados, assim como o conhecimento dos possíveis efeitos de sentido gerados através da integração das mesmas. Devemos desenvolver nos aprendizes a sensibilidade a pontos de sobreposição, diferenças e justaposição, através do uso das várias mídias, e também a capacidade de avaliar criticamente essa ampla gama de informações, a fim de que os aprendizes sejam capazes de perceber, de forma mais rica e eficiente, os usos e significados das palavras, os quais são carregados de cultura, valores ideológicos e visões de mundo. Caso esse trabalho crítico com os aprendizes não seja feito, corre-se o risco deste se perder ou ter sua atenção dividida entre as informações hipermodais apresentadas, o que poderá leválo a uma percepção fragmentada e não integrada do insumo, prejudicando, assim, o aprendizado.

Uma outra questão pedagógica que deve ser contemplada em um modelo de competência lexical voltado para o aprendizado através da hipermídia é o desenvolvimento de competências técnicas para a navegação nesse novo ambiente, o que proporcionará o acesso 
mais rápido e eficiente às mensagens hipermodais disponibilizadas. Mais especificamente, o aprendiz deve possuir conhecimentos técnicos que o capacitem a instalar e usar os programas necessários para o acesso ao material, como por exemplo o realplayer windows media player, programas que permitem executar arquivos de áudio e vídeo; entre outros. Assim, de nada vale um material rico em mídias, se o aprendiz não consegue interagir com ele. Tais recursos acabam sendo subutilizados, e, conseqüentemente, o alcance dos objetivos propostos comprometido.

Em síntese, um modelo de competência lexical para orientar o ensino e a construção de material pedagógico para o ambiente hipermídia requer, além das dimensões de conhecimento e de uso que compõem um conceito rico de competência lexical, uma dimensão tecnológica. Isto é, uma dimensão que contemple o oferecimento, ao aprendiz, de um letramento para o meio hipermidiático, levando-o, assim, a ser um participante mais motivado e competente para navegar e explorar esse novo ambiente. Além disso, levar o aprendiz a compreender como o complexo de informações multimodais, disponibilizado pela hipermídia, pode produzir significados múltiplos e complementares, para que, assim, possa interagir de forma crítica com a multiplicidade, entendendo e usando este ambiente como um meio de expressão e comunicação.

\section{CONCLUSÃO}

Dada a relevância de um modelo de competência lexical para orientar o aprendizado do léxico, neste trabalho busquei refletir e propor um modelo voltado para o ambiente hipermídia. Ou seja, fornecer, para professores e pesquisadores, subsídios teóricos para nortear o ensino e aquisição do léxico em LE em ambiente hipermídia. A discussão inicial objetivou caracterizar a hipermídia, destacando suas vantagens pedagógicas para o aprendizado. Ressaltou-se que o ambiente hipermídia permite que o aprendiz acesse o material disponibilizado de acordo com suas necessidades, interesses e 
dificuldades, além de promover contextos ricos e motivantes para a sistematização, reiteração e ampliação de informações. Posteriormente, pesquisas sobre o uso da hipermídia para o ensino e aquisição da LE foram discutidas, destacando-se a relevância de tal ambiente.

A relevância da hipermídia para o ensino e aquisição do léxico, apontada pela literatura, demanda, portanto, um modelo de competência lexical voltado para este novo contexto de aprendizagem. Nesse sentido, busquei discutir no presente trabalho, considerando as particularidades do meio hipermidático, algumas competências e aspectos do conhecimento que devem nortear o ensino do léxico.

A partir da revisão crítica de alguns modelos propostos por teóricos da linguística aplicada para a sala de aula "tradicional", com ênfase particular nos modelos de Richards (1976) e de Scaramucci (1995), destaquei, inicialmente, uma dimensão de conhecimento para compor o modelo lexical para o ambiente hipermídia, que abarca os níveis lexical, sintático, morfológico e semântico, e uma dimensão de uso, no nível pragmático-discursivo. Segundo uma perspectiva de ensino/aquisição implícitos e explícitos, aspectos do conhecimento lexical que podem ter o seu aprendizado beneficiado pelo uso da hipermídia foram apontados. A essa dimensão do conhecimento foi acrescida uma outra - uma dimensão a nível da tecnologia. Isto é, uma dimensão que contempla tanto o desenvolvimento de competências no uso da tecnologia, assim como o diálogo com as informações hipermidiáticas disponibilizadas através dela.

Desta forma, a construção de material hipermídiático para o ensino e a aquisição do léxico deve ser norteada por esse conjunto de conhecimentos e competências, a fim de que os aprendizes possam melhor se beneficiar dos contextos hipermodais em direção a construção de uma base lexical. Nesse sentido, exemplos concretos de atividades que ilustrem o desenvolvimento de tais competências e conhecimentos são necessários, a fim de fornecer subsídios práticos para o professor preparar e ou selecionar o material instrucional, uma questão de pesquisa que já está sendo investigada. 


\section{NOTAS}

* O estudo aqui apresentado é uma versão modificada e ampliada de trabalho apresentado na mesa redonda "Avaliação no contexto de língua e literatura de língua inglesa" do XVIII ENPULI e XXXIII SENAPULLI/2005, realizado em Fortaleza, Ceará.

1 "Communication has always been multi-semiotic. What is happening at the moment is therefore not in itself new; and yet it is a significant change". (KRESS, 1997: 60)

2 O termo "aprendizado implícito", no presente trabalho, refere-se ao aprendizado de palavras mesmo quando a atenção do aprendiz não está voltada para tal. O termo "aprendizado explícito", diferentemente do implícito, tem como foco o aprendizado de vocabulário por meio de estratégias e exercícios específicos.

${ }^{3}$ Concordances são contextos de uso da língua fornecidos pelos programas concordancers.

${ }^{4}$ Famílias de palavras consistem de um núcleo (headword), suas formas flexionadas e as formas derivadas intimamente relacionadas a ele.

${ }^{5}$ Componentes que constituem o conceito rico de vocabulário de Richards, derivados da lingüística teórica das décadas de 60 e 70:

Quadro 2.9. Pressuposições sobre o conhecimento lexical do falante nativo (RICHARDS, 1976).

1. O falante nativo de uma língua continua expandindo seu vocabulário na idade adulta, embora haja comparativamente pouco desenvolvimento da sintaxe;

2. Conhecer uma palavra significa saber o grau de probabilidade de encontrar essa palavra na fala ou na escrita. Para muitas palavras nós também "sabemos" os tipos de palavras mais prováveis de se associarem a ela;

3. Conhecer uma palavra implica conhecer as limitações impostas ao seu uso de acordo com as variações da função e de situação;

4. Conhecer uma palavra significa conhecer o comportamento sintático associado àquela palavra;

5. Conhecer uma palavra pressupõe conhecimento de sua forma subjacente e das derivações que podem ser feitas a partir dela;

6. Conhecer uma palavra pressupõe conhecimento de uma rede de associações entre essa palavra e outras na língua; 
7. Conhecer uma palavra significa conhecer seu valor semântico;

8. Conhecer uma palavra significa conhecer muitos dos diferentes significados associados a ela. (Scaramucci, 1995:78).

6 "(...) it is to suggest that in preparing teaching materials we begin with a rich concept of vocabulary."

${ }^{7}$ Cabe destacar aqui a necessidade de mais estudos que apontem a relevância da hipermodalidade para o ensino/aquisição de outros aspectos do conhecimento lexical.

\section{REFERÊNCIAS BIBLIOGRÁFICAS}

ALDERSON, J. C. Reading in a foreign language: a reading problem or a language problem. In: ALDERSON, J. C.; URQUHART, A. H. (Ed.). Reading in a foreign language. New York: Longman, 1984. p. 1-7.

AL-SEGHAYER, K. The effect of multimedia annotation modes on L2 vocabulary acquisition: a comparative study. Language Learning and Technology, v.1, n. 5, p. 202-232, 2001.

BRAGA, D. B. A natureza do hipertexto e suas implicações para a liberdade do leitor e o controle do autor nas interações em ambiente hipermídia". Revista da ANPOLL. São Paulo:USP, v. 1, n.15, p. 65-86, 2003.

A comunicação interativa em ambiente hipermidia: as vantagens da hipermodalidade para o aprendizado no meio digital. In: MARCUSCHI, L. A.; XAVIER, A. C. (Org.). Hipertexto e-Gêneros Digitais: novas formas de construção do sentido. Rio de Janeiro: Editora Lucerna, 2004. p. 144-162.

BRETT, P. Multimedia for listening comprehension: the design of a multimediabased resource for developing listening skills. System, v. 1, n. 23, p. 77-85, 1995.

CHUN, D. M.; J. L. PLASS. Effects of multimedia annotations on vocabulary acquisition. The Modern Language Journal, v. 2, n. 80, p. 183-198, 1996.

$\mathrm{COBB}, \mathrm{T}$. Is there any measurable learning from hands-on concordancing? System, v. 3, n. 25, p. 301-315, 1997.

FENDER, M. A review of L1 and L2/ESL word integration skills and the nature of L2/ESL word integration development involved in lower-level text processing. Language Learning, v. 2, n. 51, p. 319-396, 2001.

HARDISTY, D.; WINDEATT, S. CALL. Resource books for teachers. Oxford: Oxford University Press, 1989. 
KNIGHT, S. Dictionary use while reading: the effects on comprehension and Vocabulary for students of different verbal abilities. The Modern Language Journal, n. 78, p. 286-299, 1994.

KRESS, G. Visual and verbal modes of representation in electronically mediated communication: The potentials of new forms of text. In: SNYDER, I. (Org.). Page to screen: taking literacy into the electronic era. Sydney: Allen and Unwin, 1997. p. 53-79.

; L. VAN LEEWEN. Reading images: the grammar of the visual design. London: Routledge, 1996.

LAUFER, B. How much lexis is necessary for reading comprehension? In: ARNAUD, P. J. L.; BEJOINT, H. (Ed.). Vocabulary and Applied Linguistics. Basingstoke: Macmillan, 1991. p. 126-132.

The lexical plight in second language reading. In: COADY, J.; HUCKIN, T. N. Second Language Vocabulary Acquisition. Cambridge: Cambridge University Press, 1997. p. 20-34.

; H. M. HILL. What lexical information do L2 learners select in a CALL dictionary and how does it affect word retention? Language Learning \& Technology 3(2), 2000: 58-76.

LEMKE, J.L. Travels in hypermodality. Visual communication, v. 1, n. 3, p. 299-325, 2002.

LEWIS, M. (Ed.). Teaching collocations: further developments in the lexical approach. England: Hove: Language Teaching Publications, 2000.

LYMAN-HAGER, et al. Une Vie de Boy: Interactive reading in French. In: BORCHARDT, F. L.; JOHNSON, E. M. T. (Ed.). Proceedings of the CALICO Annual Symposium on "Assessment", p. 93-97, 1993.

MAYER, E. R. Multimedia Learning. Cambridge: Cambridge University Press, 2001.

MESKILL, C. Listening skills development through multimedia. Journal of Educational Multimedia and Hypermedia, v. 2, n. 5, p. 179-201, 1996.

NATION, I. S. P. ; WARING, R. Vocabulary size, text coverage and word lists. In: SCHMITT, N.; MCCARTHY, M. (Ed.). Vocabulary: description, acquisition and pedagogy: Cambridge: Cambridge, University Press, 1997. p. 6-19.

RICHARDS, J. C. The role of vocabulary teaching. TESOL Quartely. v. 1, n. 10, p. 77-89, 1976. 
SCARAMUCCI, M. V. R. O papel do Léxico na Compreensão em Leitura em Lingua Estrangeira: Foco no produto e no processo. 1995. $326 \mathrm{f}$. Tese de Doutorado (Lingüística) - Instituto de Estudos da Linguagem, Universidade Estadual de Campinas, Campinas.

SCHMITT, N. Tracking the incremental acquisition of second language vocabulary: a longitudinal study. Language learning, v. 2, n. 48, p. 281-317, 1998.

SCHMITT, N.; MEARA, P. M. Researching vocabulary through a word knowledge framework: word associations and verbal suffixes. Studies in Second Language Acquisition, v. 1, n. 19 p. 17-36, 1997.

; McCARTHY, M. Vocabulary: description, acquisition and pedagogy. Cambridge: Cambridge University Press, p. 199-227, 1997.

SOUZA, P. O uso da hipermídia para o ensino e a aquisição lexical no contexto da leitura em lingua estrangeira. 293 f. Tese de Doutorado (Lingüística Aplicada) - Instituto de Estudos da Linguagem, Universidade Estadual de Campinas, Campinas, 2004.

THURSTUN, J.; CANDLIN, C. Concordancing and the teaching of the vocabulary of academic English. English for Specific Purposes v. 3 n 17 , p. 267-280, 1998.

WARSCHAUER, M. Electronic Literacies: Language, Culture, and Power in Online Education. London: Lawrence Erlbaum Associates Publishers, 1999.

ZÄHNER, C.; GUPTA G.; OLOHAN, M. Lexical resources in CALL Computers Education, v. 1, n 23, p. 75-80, 1994. 